\title{
Rehabilitation Sciences Doctoral Education: A Study of Audiology, Speech-Language Therapy, and Physical Therapy Students' Research Self-Efficacy Beliefs
}

\author{
Rubini Pasupathy \\ Texas Tech University Health Sciences Center, Texas, United States
}

\begin{abstract}
Purpose: The primary purpose of this study is to add to the existing knowledge base on the research self-efficacy beliefs and research productivity of doctoral students in Rehabilitation Sciences, and its influence on research productivity. Identifying and understanding the research beliefs of Rehabilitation Sciences doctoral students will provide a better understanding of the factors that facilitate research consumption and productivity with implications for improving and enhancing Rehabilitation Sciences doctoral education.
\end{abstract}

Methods: This study employed a convenience sample of doctoral students at a public research institution of higher education enrolled in Rehabilitation Sciences programs that include; Doctor of Audiology, Communication Sciences and Disorders PhD, Physical Therapy Doctor of Science-Research Track, Physical Therapy Doctor of Science-Educational Track, and PhD in Rehabilitation Sciences. The Research Self-efficacy Inventory was utilized to measure the research self-efficacy of doctoral students in Rehabilitation Sciences programs.

Results: Research track doctoral students compared to clinical doctoral students reported higher research self-efficacy and research productivity.

Conclusions: Mastery and vicarious experiences may have contributed to increasing the research self-efficacy beliefs of research track doctoral students.

Keywords: Research self-efficacy, Speech-language pathology doctoral education, Doctor of Audiology, Research productivity, Research consumption

\section{INTRODUCTION}

Advances in medical science and technology, the change in prevalence from acute illnesses to chronic conditions, and shift in focus from inpatient to ambulatory care have advanced the job functions of Rehabilitation Sciences professionals. The job functions of Rehabilitation Sciences professionals in the past was primarily that of a clinician with treatment skills, however, present day clinicians require expertise in evaluation, research, administration, and education [1]. Correspondingly the entry level educational requirements of Rehabilitation Sciences professionals have expanded from undergraduate to doctoral degrees.

Rehabilitation Sciences professionals need to be trained to be effective evidencebased practitioners, the current gold standard of clinical practice [2]. Clinical outcomes are highly dependent on clinicians' comprehension, assimilation and production of new research information of clinical knowledge and skills. Understanding, conducting,

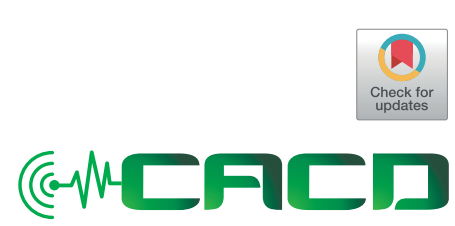

Received: January 31, 2018 Accepted: April 13, 2018

Correspondence:

Rubini Pasupathy

Texas Tech University Health Sciences Center, Texas, United States Tel: +325-696-0657 E-mail: rubini.pasupathy@ttuhsc.edu

(C) 2018 The Korean Association of SpeechLanguage Pathologists

This is an Open Access article distributed under the terms of the Creative Commons Attribution NonCommercial License (http://creativecommons.org/ licenses/by-nc/4.0/) which permits unrestricted noncommercial use, distribution, and reproduction in any medium, provided the original work is properly cited. 
and disseminating research are among the primary skills developed in Rehabilitation Sciences doctoral programs. With an understanding of the pressures that comes with being a clinician or a researcher, Rehabilitation Sciences doctoral programs seek to assist their doctoral students in developing the knowledge and skills needed to be effective consumers and producers of research. Therefore norms of productive research behavior should be instilled in all Rehabilitation Sciences students throughout their doctoral education.

However, despite developing the knowledge and skills needed to be consumers and producers of research, new doctoral graduates may not be confident in their capabilities to comprehend, develop, conduct, and publish research findings [3]. According to Bandura [4] the acquisition of knowledge and skills does not necessarily translate into effective execution, especially when the integration of complex sub skills is required. For knowledge to transform into action, self-referent thought is required. Effective research comprehension and production involve the orchestration and continuous improvisation of multiple sub-skills. Individuals examine their operative capabilities and form beliefs about their confidence to complete the various tasks successfully. These beliefs about their capabilities influence their actions, by regulating their motivation and the initiation of the various tasks [5]. Therefore an individuals' belief about their research understanding and capabilities regulates their research behavior including research consumption and production.

Confidence in an individual's research capabilities has been found to be positively correlated with his or her research productivity [6-11]. This positive relationship suggests that beliefs about research capabilities influence research behaviors. Individuals with high research self-efficacy beliefs are more productive and persevere through obstacles when compared to individuals who lack confidence in their research capabilities. However, there is a dearth of information on the research selfefficacy beliefs of doctoral students in the Rehabilitation Sciences field. Specifically, the differences between research selfefficacy beliefs of clinical versus research doctoral Rehabilitation Sciences students have not been investigated.

The primary purpose of this article is to add to the existing knowledge base on the research self-efficacy of clinical and research Rehabilitation Sciences doctoral students' confidence in their ability to understand, consume, and conduct research. First, the definitions of the constructs of self-efficacy and research self-efficacy will be presented. Followed by a summary of the findings and discussion of a study designed to investigate Rehabilitation Sciences doctoral students' research self-efficacy beliefs.

\section{Theoretical framework}

The theoretical framework underlying this study is social cognitive theory. Perceived self-efficacy refers to "beliefs in one's capabilities to organize and execute the courses of action required to produce given attainments" [4]. Self-efficacy beliefs are perceptions of confidence of ability in performing a specific task and vary according to task generality [12]. Therefore, it is possible for a doctoral student to be highly efficacious about searching an electronic database for existing literature about a particular research topic but not be efficacious about understanding the statistics or results in the literature.

Researchers in various disciplines have studied self-efficacy [13], including healthcare researchers. Examples of published research in the area of Rehabilitation Sciences include studies of self-efficacy in the context of speech-language pathology [14-17], audiology [18,19], and occupational therapy [20,21].

The popularity of the self-efficacy construct is in part due to its ability to predict future behavior. Self-efficacy is a predictor of performance [12]. Research indicates that there is a significant correlation between self-efficacy and performance on specific tasks [5]. Highly efficacious individuals have higher aspirations, strong commitment to their goals, and are not easily discouraged by obstacles and failure [4]. The effort invested in a task is regulated by an individual's belief of their ability to perform the task. Research also indicates that the persistence in continuing with the task is correlated to self-efficacy [12].

The research self-efficacy beliefs of graduate students and current researchers have received increased attention in the past decade [11,22]. Research self-efficacy has been studied in relation to research experience, interest in research, time spent in graduate school, research training environment, gender, and research productivity [7-9,11,22-27].

The length of time spent in graduate school has been reported to be a predictor of research self-efficacy among graduate students [8,11,23,25]. Gelso [25] studied the attitudes towards research among clinical psychology graduate students. The results indicate that graduate students that were new to the graduate program were not very efficacious about conducting research. As to be expected, self-efficacy beliefs increased as students progressed in the program. Gelso [25] recommends that graduate training programs incorporate early active involvement in clinical and research doctoral training. 
Apart from the length of time spent in graduate school, graduate students' research self-efficacy is also influenced by their experience and exposure to research in graduate school. Bieschke et al. [28] report that research experience is a predictor of research self-efficacy.

The relationship between research self-efficacy and research productivity has been widely studied. Research self-efficacy is positively correlated to research productivity [6$11,22]$. Research self-efficacy is a significant predictor of research productivity among doctoral students $[7,8,11,28]$ and faculty members $[9,22]$.

Phillips and Russell [11] studied research self-efficacy and productivity of graduate students in clinical psychology. Phillips and Russell found a significant correlation between research self-efficacy and productivity, for the total sample $(\mathrm{r}=0.45, p<0.001)$ and for beginning $(\mathrm{r}=0.33, p<0.001)$ and advanced $(\mathrm{r}=0.50, p<0.001)$ student subgroups. The increase in correlation between research self-efficacy and productivity as students advance in graduate school is consistent with Bandura's [12] predictions of self-efficacy theory. As students progress through graduate school there are more opportunities to observe, understand, emulate, and conduct research. These enactive and vicarious experiences contribute to research self-efficacy and productivity.

Pasupathy and Siwatu [10] examined the nature of researchself efficacy among faculty members in the fields of social and behavioral sciences. They report that there is a relationship between research self-efficacy beliefs and the research behavior of faculty members. Faculty members that conduct both qualitative and quantitative research are efficacious about general research tasks, however, faculty members that conduct qualitative research are more efficacious about completing qualitative research tasks and faculty members that conduct quantitative research are more efficacious about completing quantitative research tasks. Their findings highlight the fact that self-efficacy beliefs pertain to specific tasks and are formed and highly influenced by mastery experiences. Pasupathy and Siwatu [10] further examined the relationship between research self-efficacy beliefs and research productivity among faculty members. A significant correlation between research self-efficacy and publication of research studies in peer reviewed journals $(r=0.59, p<0.05)$ for faculty that primarily conduct qualitative research, research self-efficacy and total research productivity $(\mathrm{r}=0.59, p<0.05)$ for faculty that primarily conduct quantitative research and research self-efficacy and publication of book chapters $(\mathrm{r}=0.37, p<0.05)$ for faculty member that conduct both qualitative and quantitative research was reported. The significant but varying strengths of correlation between research self-efficacy and the different research products, is consistent with past research and supports the predictive nature of self-efficacy beliefs. Further, these findings reflect that there is a positive relationship between research self- efficacy beliefs and the research product that is most valued by faculty members depending on the type of research they conduct.

Research productivity has been studied extensively. A significant amount of research has been conducted on research productivity since the early 1970 s $[29,30]$. Studies on research productivity have utilized a wide variety of measures [31]. These measures range from the simple but objective standard of number of articles published in select few journals to complex weighted averages of publications such as journal articles, and book chapters.

\section{METHODS}

\section{Participants}

This study employed a convenience sample of doctoral students at a public research institution of higher education enrolled in Rehabilitation Sciences programs that include; Doctor of Audiology, Communication Sciences and Disorders PhD, Physical Therapy Doctor of Science-Research Track, Physical Therapy Doctor of Science-Educational Track, and $\mathrm{PhD}$ in Rehabilitation Sciences. Participants enrolled in programs where the objective was to provide research training as a basis for clinical practice and clinical education, were categorized as clinical doctoral students. These included Doctor of Audiology, Doctor of Physical Therapy and Physical Therapy Doctor of Science-Educational Track. Participants that were enrolled in programs with the objective to conduct independent clinical and/or basic research upon graduation were categorized as research doctoral students. These programs included the Communication Sciences and Disorders PhD, $\mathrm{PhD}$ in Rehabilitation Sciences, and the Physical Therapy Doctor of Science-Research Track. A total of 45 doctoral students participated in the study. Of the 45 participants, 33\% $(n=15)$ were enrolled in research doctoral programs and $67 \%$ $(n=28)$ were enrolled in a clinical doctoral programs.

\section{Variables}

The dependant variables in this study were Rehabilitation Sciences doctoral students' self-efficacy and research productiv- 
ity. For the purposes of this study, research self-efficacy was operationally defined as the participants' Research Self-Efficacy Inventory indices.

\section{Instrumentation}

\section{Measures}

The Research Self-efficacy Inventory (RSEI) [10] was utilized to measure the research self-efficacy of doctoral students in Rehabilitation Sciences programs. The RSEI contains the following four domain specific research self-efficacy measures: General Research Self-Efficacy Scale (GRSE), Quantitative Research Self-Efficacy Scale (QnRSE), Qualitative Research SelfEfficacy Scale (QLRSE), and Mixed Methods Research Self-Efficacy (MMRSE). For the purpose of this study, the first three measures were used. These three measures contain 31 items. All items in the scale begin with the same stem: "How confident are you that you can....." For each item, participants were asked to indicate a degree of confidence for executing the specific task using a scale ranging from 0 (no confidence at all) to 100 (completely confident).

The GRSE is designed to assess participants' beliefs in their capabilities to design and conduct a study in the social and behavioral sciences. The scale consists of 10 items in which participants are asked to rate how confident they are in their ability to execute general research tasks associated with Creswell's [32] six steps in the research process. These processes include: identifying a research problem, reviewing the literature, specifying a purpose, collecting data, analyzing and interpreting data, and reporting the results of the study. Sample items in the scale include: "select an appropriate research design that will answer specific research questions" and "analyze data to provide answers to existing research questions." A total score of participant's responses was generated through the summation of the 10 items within this scale. Total scores could range from 0 to 1,000 . Reliability analysis of the GRSE indicate that the scale has good internal consistency with a Cronbach alpha of 0.94 [10].

The QnRSE was created to assess participants' beliefs in their capabilities to carry out tasks associated with designing and conducting a quantitative research study. Sample items in the 13-item scale include: "create a data file using statistical software program (e.g., SPSS)" and "collect quantitative data using techniques that are suitable in answering research questions." A total score of participant's responses was generated through the summation of the 13 items with in this scale. Total scores could range from 0 to 1,300 . The QnRSE has a
Cronbach's alpha of 0.97 , which signifies that the scale has good internal consistency [10].

The QIRSE was created to assess participants' beliefs in their capabilities to carry out tasks associated with designing and conducting a qualitative research study. Sample items in the 8-item scale include: "implement the appropriate sampling procedure after data collection has begun in a qualitative study" and "conduct the appropriate qualitative analyses to answer specific research questions." A total score of participant's responses was generated through the summation of the 8 items with in this scale. Total scores could range from 0 to 800 . The results of a reliability analysis suggest high internal consistency, with a Cronbach alpha of 0.96 [10].

Participants' responses to each of the items within each scale was combined to generate a total score for each domain. Participants with higher total scores were judged to have more confidence in their ability to conduct the specific research tasks within each domain. Total research self-efficacy scores were derived through a summation of domain scores.

A productivity questionnaire was used to determine the types of research tasks each participant had completed in the doctoral program. Quantity and type of research product were the only measures of productivity in this research project. Participants self reported participation in research projects, the number of research presentations submitted and accepted, reports and publications completed and research based grants received. Total Research Productivity (TRP) was calculated by summation of research products reported.

\section{Background questionnaire}

In addition to the RSEI, participants completed a written background questionnaire. The background questionnaire consisted of items related to the participants' gender, year of doctoral education, completion of credit hours, completion of graduate level research design credit hours, preference of research method, doctoral degree, opportunities to conduct research, and satisfaction with research feedback received. The information acquired from this questionnaire facilitated the descriptive analysis of the data.

\section{Procedures}

Following institutional review board approval, the survey instruments were administered in the various classrooms of the doctoral programs. The participants were given both oral and written instructions related to the survey instrument. Participants were informed that participation was voluntary and 
would not affect any class grades. Neither the instructors of the classes, nor the investigators were present in the classroom when students completed the survey. Surveys were deidentified and separated from informed consent forms.

\section{RESULTS}

This study used a standard group comparison design with two dependent variables; research self-efficacy and research productivity. Descriptive statistics (i.e., means and standard deviations) for various groups and sub groups were calculated. Spearman Rho correlation was used to investigate the relationship between research self-efficacy and research productivity.

The respondents who completed all survey instruments consisted of a total of 46 doctoral students. Of the 46 participants, 37\% ( $\mathrm{n}=17)$ were enrolled in research doctoral programs and $63 \%(\mathrm{n}=29)$ were enrolled in a clinical doctoral programs. Clinical doctoral participants consisted of 26 Doctor of Audiology students, and 3 Doctor of Science in Physical Therapy- Education Track students. Research doctoral participants consisted of $6 \mathrm{PhD}$ in Communication Sciences and Disorders students, $9 \mathrm{PhD}$ in Rehabilitation Sciences students, and 2 Doctor of Science in Physical Therapy- Research Track students. $71.7 \%$ of the participants were female and $28.3 \%$ were male. Sixty-nine point six percent of the respondents had completed 13 or more semester credit hours prior to the completion of the survey, with a mean of $1.82(\mathrm{SD}=1.07)$ years in the doctoral program. Across participants $67.4 \%$ $(\mathrm{n}=31)$ reported that they are currently working on a research project, $13.00 \%(\mathrm{n}=6)$ on an educational project, and $4.3 \%$ $(\mathrm{n}=2)$ on a dissertation project. Adequate opportunities to conduct research in their individual doctoral programs was reported by $95.7 \%(n=44)$ of the participants. When conducting research, $82 \%(\mathrm{n}=37)$ of the respondents reported feeling either stress, nervousness, anxiety or stomach or body aches. Respondents reported that the feedback received from the chairperson and the other doctoral committee members influenced their confidence to conduct research $(89.1 \%, \mathrm{n}=40)$.

\section{Nature of research and clinical track doctoral students' research self-efficacy beliefs}

Overall, the results indicated that participants had a wide range of levels of confidence in completing research tasks successfully. The RSEI for all participants ranged from 12.42 to $96.23(\mathrm{M}=59.55, \mathrm{SD}=23.78)$.
An independent sample t-test was conducted to compare the research self-efficacy beliefs of clinical doctoral students and research doctoral students. There was a significant difference $(\mathrm{t}(44)=5.55, p<0.01)$ in the RSEI between clinical track participants $(\mathrm{M}=46.79, \mathrm{SD}=19.88)$ and research track participants $(\mathrm{M}=81.31, \mathrm{SD}=10.00)$. The significant difference in the global measure of research confidence indicates that clinical doctoral students were less confident about successfully completing research tasks than research doctoral students.

\section{Research self-efficacy beliefs across task domains}

There was wide variability in research self-efficacy beliefs by research task domain for all participants. Doctoral students were most confident about successfully completing general research tasks ( $\mathrm{M}=68.97, \mathrm{SD}=3.72)$, and were least confident about completing qualitative research tasks $(\mathrm{M}=53.87, \mathrm{SD}=$ 3.72).

A one-way ANOVA was performed to evaluate the effect of task domain on research self -efficacy beliefs for all students. Results indicate that there was a significant main effect for task domain $(\mathrm{F}(2,136)=4.85, p<0.01)$. Post-hoc Tukey HSD test $(p<0.05)$ with a Bonferroni correction was used to determine significance among mean scores across the three domains. Results revealed that the GRSE domain index (M= 68.97) was significantly higher in comparison to QIRSE $(\mathrm{M}=53.87)$ and $\mathrm{QnRSE}(\mathrm{M}=55.79)$ domain indices. Further, there was no significant difference between QIRSE domain index $(M=53.87)$ and QnRSE domain index $(M=55.79)$.

Among all research tasks within each domain, participants were most efficacious about searching an electronic database for existing literature about a particular research topic. Participants report being least confident about using software program to perform qualitative and quantitative data.

\section{Nature of research and clinical track doctoral student' research productivity}

An independent sample t-test was conducted to compare the research productivity of clinical doctoral students and research doctoral students. Overall, doctoral students in the research track were significantly more productive than doctoral students in the clinical track $(\mathrm{t}(44)=4.05, p<0.001)$.

Among clinical track participants, TRP ranged from 0.00 to $28.00(\mathrm{M}=0.96, \mathrm{SD}=1.40)$. Clinical track participants were most productive in working with a faculty member in designing and implementing a research study $(\mathrm{n}=9)$, participating in a research team $(\mathrm{n}=8)$, and individually designed and im- 
plemented a research study $(n=4)$.

Within research track participants, TRP ranged from 0.00 to $46.00(\mathrm{M}=9.17, \mathrm{SD}=10.82)$. Research track participants were most productive in participating in a research team $(n=34)$, working with a faculty member in designing and implementing a research study $(\mathrm{n}=23)$, and submitting a literature review to be considered for publication $(n=13)$.

As there were multiple research products, a Multivariate test (Wilk's Lambda) was conducted to examine research productivity across various research products for clinical and research track doctoral students. Results indicate that doctoral track had a significant effect $(\mathrm{F}(1,44)=5.73, p<0.05)$ on all of the various research products. Among the research products, the greatest difference between the clinical doctoral students and research doctoral students was seen in the research product participated in a research team $(\mathrm{F}(1,44)=26.05, p<0.001)$ and worked with a faculty member in designing and implementing a research study $(\mathrm{F}(1,44)=19.64, p<0.001)$.

\section{Relationship between research self-efficacy beliefs and research productivity}

The non-parametric Spearman rank-order correlation coefficients were calculated to assess the relationship between research self-efficacy and research productivity. The non-parametric Spearman rank-order correlation coefficient was used because the data obtained was skewed for both the research self-efficacy and productivity variables. For all participants, there was a significant correlation between total research productivity (TRP) and RSEI ( $\mathrm{r}=0.59, p<0.01)$, TRP and GRSE $(\mathrm{r}=0.62, p<0.01)$, TRP and QLE $(\mathrm{r}=0.46, p<0.01)$, and TRP and QnRSE $(\mathrm{r}=0.59, p<0.01)$. Further there was significant correlation between RSEI and individually designing and implementing a research study $(\mathrm{r}=0.38, p<0.01)$, working with a faculty member in designing and implementing a research study $(\mathrm{r}=0.50, p<0.01)$, participation in a research team ( $\mathrm{r}=0.70, p<0.01)$, and submitting a literature review to be considered for publication $(\mathrm{r}=0.45, p<0.01)$.

For participants in the research track, there were no significant correlation between research self-efficacy and total research productivity. However, there was significant correlation between RSEI and submitting a conceptual paper to be considered for publication $(\mathrm{r}=0.47, p<0.01)$. Further there was a significant correlation between QLE and published your work in a non peer reviewed journal $(\mathrm{r}=0.49, p<0.01)$.

For participants in the clinical track there was significant correlation between RSEI and TRP $(r=0.40, p<0.01)$, and
RSEI and working with a faculty member in designing and implementing a research study $(\mathrm{r}=0.40, p<0.01)$. Further there was significant correlation between and GRSE and TRP $(\mathrm{r}=0.49, p<0.01)$, GRSE and worked with a faculty member in designing and implementing a research study $(r=0.39$, $p<0.01)$, and GRSE and participated in a research team $(\mathrm{r}=$ $0.46, p<0.01)$.

\section{DISCUSSION}

The major aim of this study was to explore whether type of doctoral degree (research and clinical) within Rehabilitation Sciences programs was associated with differential gains in students' confidence with research comprehension and skill, and research productivity. The standard group comparison design used in this study of a convenient sample was limited to several known threats to internal validity; most relevant were differential selection, history, maturation, and regression effects. However, the study findings point to several useful implications for Rehabilitation Sciences educators who are aiming to enhance their research curricula and for researchers who study the scholarship of research instruction in professional doctoral programs.

The descriptive data used to answer the first research question revealed that doctoral students in general were moderately confident in their ability to conduct research tasks. Doctoral students were particularly confident in their ability to conduct general research tasks (e.g., indentify a research problem that can be researched scientifically, and search an electronic database for existing literature about a particular research topic) and were least confident about their ability to conduct qualitative research tasks (e.g., Analyze qualitative data using a software program (e.g., NVivo, NUD*IST), and implement strategies to enhance the trustworthiness of a qualitative study). Further, research track doctoral students were more confident about completing research tasks successfully than clinical doctoral students. According to Bandura [12], mastery and vicarious experiences are powerful sources of self-efficacy information. Although both clinical and research track doctoral students are required to complete research credit hours, clinical track doctoral students are required to complete fewer research credit hours than research track doctoral students. Most research projects either qualitative or quantitative include general research tasks. Therefore doctoral students through observation and practical experiences have gained confidence in conducting these tasks. Re- 
search track doctoral students also reported higher research productivity, especially in participation in research teams and working with faculty member on a research project and therefore had more opportunities for mastery and vicarious experiences. For all participants there was a moderate but significant correlation between research self-efficacy and research productivity. Research self-efficacy has been reported to be a predictor of research productivity [10], especially among graduate students [8]. The findings of this study are in line with past research that indicate a significant but moderate strength of correlation between research self-efficacy and research productivity $[10,11]$.

The major implication relates to the disparate research selfefficacy beliefs and research productivity of clinical and research doctoral students. Although practitioners with a clinical doctorate may not be conducting research projects, to be effective in their professions as clinicians they will require the knowledge, skill and ability to incorporate research in their daily practice. In recent years, evidence based practice has gained in popularity [33]. Healthcare practitioners are encouraged to evaluate and incorporate results of original research in their daily practice. One of the primary obstacles to the adoption of evidence based practice is reported to be the lack of knowledge and expertise in assessing the validity of current evidence (research) and interpreting statistical results [34]. Research indicates that the inability to formulate clinical research questions, conduct an efficient literature search, understand and discriminate between the various research designs and determine the validity of studies, and effectively apply the research findings to patient problems are some of the barriers to evidence based practice adoption [33]. Rehabilitation Sciences educators need to be aware of the relationship between exposure to research and research experience and the confidence to conduct basic research skills, and comprehend and assimilate research findings into clinical practice. There is a clear need for further investigation, into the relationship between research exposure and education, and the consumption, assimilation and production of research among Rehabilitation Sciences doctoral students. Future research on this topic should include a larger sample of Rehabilitation Sciences doctoral students from various institutions.

\section{CONCLUSION}

In this descriptive study of Rehabilitation Sciences doctoral students, we have attempted to assess students' beliefs about their confidence in comprehending and conducting research tasks and their research behaviors and productivity. The results indicate a considerable difference in the research self-efficacy beliefs and research productivity of clinical and research doctoral students. Our findings indicate that mastery and vicarious learning opportunities may enhance the understanding, consumption and production of research.

\section{REFERENCES}

1. Sheppard KF, Jensen GM. Physical therapist curricula for the 1990s: educating the reflective practitioner. Physical Therapy. 1990;9:566-573.

2. Zippoli RP, Kennedy M. Evidence-based practice among speechlanguage pathologist: attitudes, utilization and barriers. American Journal of Speech-Language Pathology. 2005;14:208-220.

3. Hanna N, Haug R, Krabbenhoft A. The self-fulfilling prophesy of the tenure/promotion policies at business colleges and schools. The Journal of American Academy of Business. 2005;7(1):53-58.

4. Bandura A. Self-efficacy: the exercise of control. New York: Freeman. 1997.

5. Bandura A. Social foundations of thought and action: a social cognitive theory. Englewood Cliffs. NJ: Prentice-Hall. 1986.

6. Bailey JG. Academics' motivation and self-efficacy for teaching and research. Higher Education Research and Development. 1999;18(3):343-359.

7. Kahn JH. Predicting the scholarly activity of counseling psychology students: a refinement and extension. Journal of Counseling Psychology. 2001;48:344-354.

8. Kahn JH, Scott NA. Predictors of research productivity and science-related career goals among counseling psychology graduate students. The Counseling Psychologist. 1997;25:38-67.

9. Landino RA, Owen SV. Self-efficacy in University faculty. Journal of Vocational Behavior. 1988;33(1):1-14.

10. Pasupathy R, Siwatu KO. An investigation of research self-efficacy beliefs and research productivity among faculty members at an emerging research university in the USA. Higher Education Research and Development. 2014;33(4):728-741.

11. Phillips JC, Russell RK. Research Self-efficacy, the research training environment, and research productivity among graduate students in counseling psychology. The Counseling Psychologist. 1994;22(4):628-642.

12. Bandura A. Self-efficacy: toward a unifying theory of behavioral change. Psychological Review. 1977;84:191-215.

13. Schunk DH, Pajares F. Self-efficacy in education revisited: empirical and applied evidence. In D. M. McInerney, \& S. V. Etten (Eds.), Big theories revisited: research on socio-cultural influences on motivation and learning (p. 115-138). Greenwhich. CT: Information Age Publishing. 2004.

14. Cherney LR, Babbitt EM, Semik P, Heinemann AW. Psychometric properties of the communication confidence rating scale for apha- 
sia (CCRSA): phase 1. Topics in Stroke Rehabilitation. 2011;18(4): 352-360.

15. Lee C, Schmaman F. Self-efficacy as a predictor of clinical skills among speech pathology students. Higher Education. 1987;16(4): 407-416.

16. Pasupathy R, Bogschutz RJ. Contemporary issues in communication science and disorders. 2013;40:151-159.

17. Rudolf S, Manning WH, Sewell WR. The use of self-efficacy scaling in training student clinicians: implications for work with stutterers. Journal of Fluency Disorders. 1983;8:55-75.

18. Meyer C, Hickson L, Fletcher A. Identifying the barriers and facilitators to optimal hearing aid self-efficacy. International Journal of Audiology. 2014;53(1):28-37.

19. Smith SL, West RL. The application of self-efficacy principles to audiologic rehabilitation: a tutorial. American Journal of Audiology. 2006;15:46-56.

20. Petzold A, Korner-Bitensky N, Salbach NM, Ahmed S, Menon A, Ogourtsova T. Increasing knowledge of best practices for occupational therapists treating post-stroke unilateral spatial neglect: result of a knowledge-translation intervention study. Journal of Rehabilitation Medicine. 2012;44(2):118-124.

21. Vax S, Schreuer N, Sachs D. Work-related self-efficacy of occupational therapists in mental health. Scandinavian Journal of Occupational Therapy. 2012;19(1):42-48.

22. Vasil L. Self-efficacy expectations and causal attributions for achievement among male and female University faculty. Journal of Vocational Behavior. 1992;41:259-269.

23. Bishop RM, Bieschke KJ. Applying social cognitive theory to interest in research among counseling psychology doctoral students: a path analysis. Journal of Counseling Psychology. 1998;45:182-188.

24. Brown SD, Lent RW, Ryan NE, McPartland EB. Self-efficacy as an intervening mechanism between research training environments and scholarly productivity: a theoretical and methodological ex- tension. The Counseling Psychologist. 1996;24:535-544.

25. Gelso CJ. On the making of a scientist-practitioner: a theory of research training in professional psychology. Training and Education in Professional Psychology. 2006;(1):3-16.

26. Pasupathy R, Siwatu KO. Fostering Confident researchers: research self-efficacy as a faculty developmental tool. International Journal of University Teaching and Faculty Development. 2011; 1(4):249-261.

27. Schoen LG, Winocur S. An investigation of the self-efficacy of male and female academics. Journal of Vocational Behavior. 1988;32 307-320.

28. Bieschke KJ, Bishop RM, Garcia VL. The Utility of the research self-efficacy scale. Journal of Career Assessment. 1996;4(1):59-75.

29. Dundar H, Lewis DR. Determinants of research productivity in higher education. Research in Higher Education. 1998;39(6):607631.

30. Toutkoushian RK, Porter SR, Danielson C, Hollis PR. Using publication counts to measure an institution's research productivity. Research in Higher Education. 2003;44(2):121-148.

31. Duffy RD, Martin HM, Bryan NA, Raquue-Bogdan TL. Measuring individual research productivity: a review and development of the integrated research productivity index. Journal of Counseling Psychology. 2008;55(4):518-527.

32. Creswell JW. Educational research: planning, conducting and evaluating quantitative and qualitative research. New York City. 2002. NY: Pearson.

33. Jette DU, Bacon K, Batty C, Carlson M, Ferland A, Hemingway RD, et al. Evidence- based practice: belief, attitudes, knowledge, and behaviors of physical therapists. Physical Therapy. 2003;83(9): 786-805.

34. Retsas A. Barriers to using research evidence in nursing practice. Journal of Advanced Nursing. 2000;31(3):599-606. 